\title{
DeGIR Quality Report 2019: Report on the treatment quality of minimally invasive methods - Interventional therapy (EVAR) of abdominal aortic aneurysms
}

\section{DeGIR-Qualitätsreport 2019: Bericht über die Behandlungsqualität minimalinvasiver Methoden - interventionelle Therapie (EVAR) von abdominellen Aortenaneurysmen}

Authors

Felix Frenzel ${ }^{10}$, Arno Bücker ${ }^{1}$, Philipp Paprottka², Jonathan Nadjiri², Andreas H. Mahnken³ ${ }^{3}$ Alexander Massmann', Peter Minko', Lothar J. Heuser ${ }^{4}$

Affiliations

1 Clinic of Diagnostic and Interventional Radiology, Saarland University Hospital and Saarland University Faculty of Medicine, Homburg, Germany

2 Department of Interventional Radiology, Technical University of Munich, München, Germany

3 Diagnostic and Interventional Radiology, University Hospital of Gießen and Marburg Campus Marburg, Germany

4 Dept. of Diagnostic und Interventional Radiology, Im Pastoratsbusch 49, Bochum, Germany

Key words quality management, interventional Radiology, aortic aneurysm, EVAR, stents, arteriosclerosis

received 11.04.2021

accepted 17.06.2021

published online 05.08 .2021

Bibliography

Fortschr Röntgenstr 2022; 194: 49-61

DOI 10.1055/a-1541-8872

ISSN 1438-9029

(C) 2021. Thieme. All rights reserved.

Georg Thieme Verlag KG, Rüdigerstraße 14,

70469 Stuttgart, Germany

Correspondence

Prof. Arno Bücker

Clinic of Diagnostic and Interventional Radiology, Saarland University Medical Center, Kirrberger Str. 100,

66421 Homburg, Germany

Tel.: +49/6841/1624600

arno.buecker@uks.eu

\section{ABSTRACT}

Purpose To analyze the quality of endovascular aortic aneurysm repair using the data of the DeGIR quality management system. Comparison of data between 2011 and 2019.

Materials and Methods A retrospective analysis of all data registered in the DeGIR quality management system of the year 2019 was performed regarding the treatment quality for endovascular aortic aneurysm repair. Registration of data was voluntary. As quality parameters indication, treatment process data and quality of results were examined. The latter was judged by treatment success, complication rates and radiation exposure.

Results Out of 189590 data sets overall 1639 cases of EVAR were registered; compared to 2011 this was an increase of 472 cases. $5.9 \%$ of these cases encompassed emergency treatments. The most frequent indication was an abdominal aneurysm with $72 \%$ of cases. In $54 \%$ of cases, the aortic diameter ranged $50-70 \mathrm{~mm}$. The rates for technical success, over all complications and major complications were $92.8 \%$, $6.7 \%$ and $6.0 \%$ respectively for all EVAR including emergency indications. In general, EVAR yielded a mortality rate of $1.2 \%$ while emergency procedures had a mortality rate of $7.3 \%$. Median dose area product and fluoroscopy time were 10503 cGy $\times \mathrm{cm} 2$ and 20 minutes respectively at a mean procedure time of 114 minutes.

Conclusion Data analysis of the DeGIR quality management system persistently showed a very high technical success rate for endovascular aortic aneurysm repair performed by interventional radiologists accompanied by a low complication rate.

\section{Key Points}

- The voluntary DeGIR quality assurance-system has reached high acceptance among interventional radiologists.

- The database has nearly 200000 submissions on record for 2019.

- EVAR by interventional radiologists has shown very high technical success as well as a low complication rate. 


\section{Citation Format}

- Frenzel F, Bücker A, Paprottka P et al. DeGIR Quality Report 2019: Report on the treatment quality of minimally invasive methods - Interventional therapy (EVAR) of abdominal aortic aneurysms. Fortschr Röntgenstr 2022; 194: 49-61

\section{ZUSAMMENFASSUNG}

Ziel Analyse der Behandlungsqualität der endovaskulären Versorgung von Aortenaneurysmen anhand der Eingaben in das DeGIR-Qualitätssicherungssystem. Vergleich der Entwicklung der Daten aus dem Qualitätsreport von 2011 und 2019. Material und Methoden Alle Registerdaten des Jahres 2019 zur Behandlungsqualität der endovaskulären Versorgung von Aortenaneurysmen (EVAR) des freiwilligen DeGIR-Qualitätssicherungssystems wurden retrospektiv ausgewertet. Als Qualitätskriterien dienten Indikation, Therapieprozess und Ergebnisqualität. Ergebnisparameter waren Therapieerfolg, Komplikationsraten und Strahlenexposition.

Ergebnisse Von insgesamt 189590 im Jahre 2019 in das Register eingepflegten Datensätzen beschreiben 1639 die
Behandlung eines Aortenaneurysmas; gegenüber 2011 erhöhte sich die absolute Zahl somit um 472 Fälle. Bei 5,9\% der Fälle handelte es sich um eine Notfallindikation. Die häufigste Indikation zur EVAR-Behandlung stellte mit $72 \%$ das abdominelle Aneurysma dar. Der Aortendurchmesser lag in $54 \%$ der Fälle zwischen 50 und $70 \mathrm{~mm}$. Bezogen auf alle EVAR einschließlich der Notfallindikationen betrug der technische Erfolg 92,8\%, während die Raten für Komplikationen gesamt 6,7\% und für Major-Komplikationen 6,0\% betrugen. Die Letalitätsrate aller EVAR betrug 1,2\% und die der Notfallbehandlungen 7,3\%. Die Mediane des Dosisflächenprodukts und der Durchleuchtungszeit lagen bei $10530 \mathrm{cGy \times cm^{2 }}$ und 20 min bei einer medianen Prozedurdauer von $114 \mathrm{~min}$.

Schlussfolgerung Die Datenauswertung des DeGIR-Qualitätssicherungssystems belegt eine konstant sehr hohe technische Erfolgsrate der durch interventionelle Radiologen durchgeführten EVAR-Prozeduren bei geringer Komplikationsrate.

\section{Introduction}

Since 1994, the German Society for Interventional Radiology and Minimally Invasive Therapy (DeGIR) has been collecting treatment data of minimally invasive radiological interventions in its voluntary quality assurance system (DeGIR QA system) [1]. The goals are to measure, assure, and improve the quality of treatment for all interventional radiology procedures [1, 2].

Participation in the DeGIR QA system is voluntary. Participation and reporting of minimum numbers in the corresponding interventions are a mandatory requirement for certification of hospitals as an Interdisciplinary Vascular Centre. This enables DeGIR to issue certificates of qualification of individuals and training institutions exclusively to appropriately qualified and experienced individuals and clinics.

The software used for documentation is continuously improved, supplemented and adapted to the development of individual interventional therapy methods based on user feedback. In 2015, there was a change of software to a new system, which temporarily led to a decrease in all reported interventions. The new system makes it possible to use the software as a basis for registry studies including long-term follow-up.

The aim of this paper is to reflect the everyday quality of care for endovascular care of aortic aneurysms using 2019 coded data and compare it to data collected in 2011 [3].

\section{Materials and Methods}

All data sets for the interventional treatment of aortic aneurysms from the DeGIR Registry from 2011 and 2019 were evaluated according to the following criteria: demographics, interdisci- plinary indication, aneurysm location and size, type of anesthesia, access routes, radiation exposure as well as success, partial success, failure and complication rates. Trends of the intervention numbers were continuously collected from the data registry for the years 2011 to 2019. The results are presented in the form of descriptive statistics with medians and interquartile range (IQR) or as a mean value with standard deviations. The information on radiation exposure is shown as box plots. In principle, the data from 2011 are placed at the end of the data from 2019 in [square brackets].

\section{Results}

\section{DeGIR data pool}

For 2019, 189590 records of interventional radiology procedures were collected. This represents an increase by a factor of 2.3 compared to the 82881 records in the 2011 DeGIR-QA system. Treatment of aneurysms by implantation of stent grafts in the various aortic segments and in other arterial aneurysms of the trunk and extremities ranks 9th among the most common interventions in the DeGIR data pool in 2019, as it did in 2011. Of the total of 2346 aneurysm treatments, typical abdominal EVAR interventions made up the largest proportion with 1639 in 2019; in 2011 there were 1167 typical EVAR interventions. The trend of documented EVAR intervention numbers from 2011 to 2019 increased by 472 cases, from 1167 to 1639 . Of 102 centres in Germany with documented EVAR treatments in 2019, 28 hospitals met DeGIR certification requirements as training centres, and 14 of these performed more than 50 procedures in 2019. 


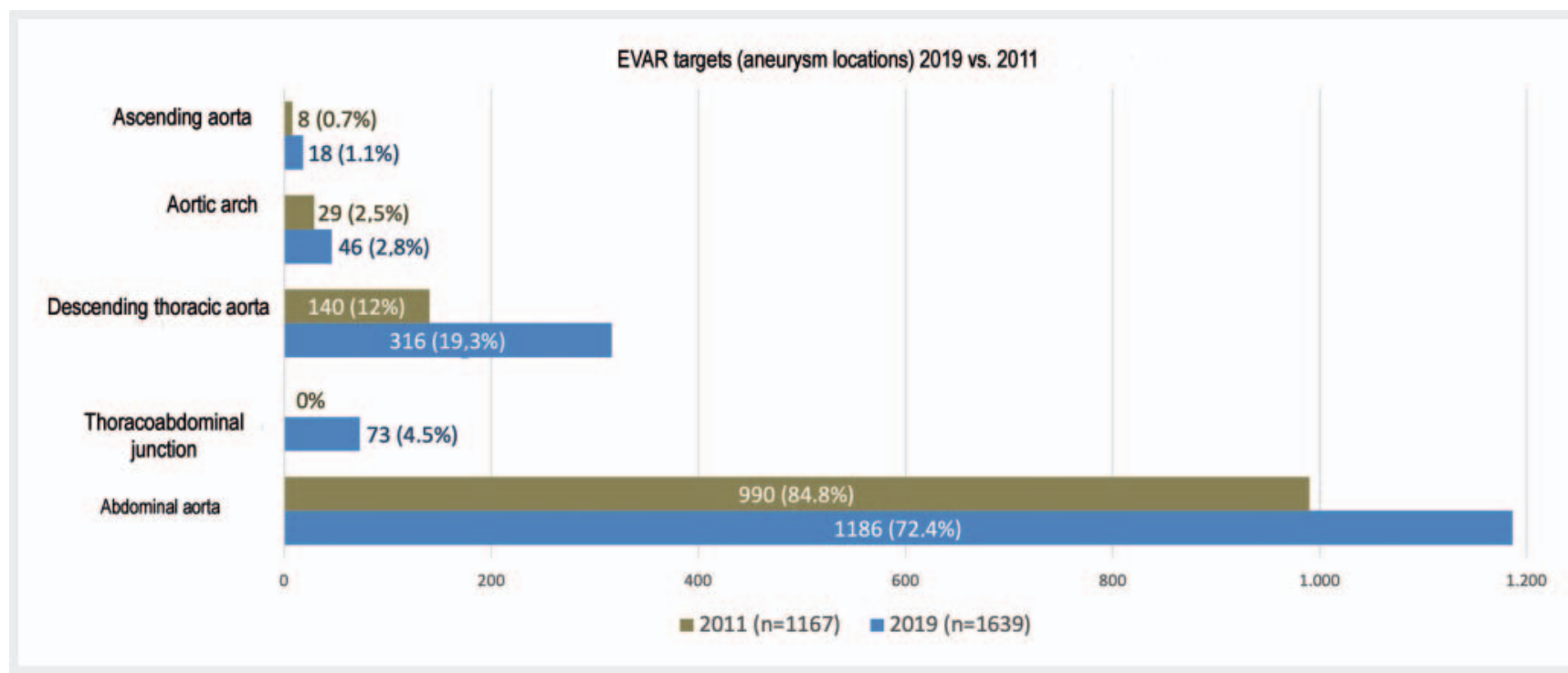

- Fig. 1 Overview of the different aneurysmal localizations of EVAR interventions in $2019(n=1639)$ compared to 2011 ( $n=1167)$. An increase in absolute numbers is seen in all aortic sections. In relative terms, a shift from the abdominal aorta to the thoracic sections is evident.

\section{Patients}

The treated patients included 1322 men [993 in 2011] and 317 women [174]) aged $16-102$ years [32-101] (mean 72.9 years [73.3], median 74.2 years [74]).

The median of the age distribution is almost identical over time. The higher proportion of women with treated AAA in 2019 is notable. While the ratio of men to women was 6:1 in 2011, it was only 4:1 in 2019.

\section{Indication}

Although only initial and single interventions were recorded in 2011, 3.8\% (63 cases) reflected multiple interventions in 2019. Compared to 2011, the proportion of emergency interventions was reduced to half in 2019. Accordingly, emergency indications outside of routine service occurred for 96 patients (5.9\%) [145 patients (12.4\%)], and the remaining 1543 patients (94.1\%) were treated during regular service hours.

Since the interdisciplinary indication is viewed by the DeGIR as an essential quality feature, related information has meanwhile become a mandatory coding item. Whereas in 2011, only 915 records (78.4\%) contained a joint indication with at least one other discipline or in the context of an interdisciplinary vascular conference, the indication for EVAR 2019 was made on an interdisciplinary basis in 1639 cases. If radiology is excluded as a coding specialty, surgery was most frequently involved in interdisciplinary indications $(92.2 \%)$ followed by anesthesiology (36.5\%) and internal medicine (13.9\%).

Even in emergencies, an interdisciplinary decision for EVAR was made in 91 cases $(95 \%)$. While the participation of internal medicine compared to elective EVAR was halved to $7.7 \%$, otherwise the same specialist disciplines were involved in almost the same proportion.

\section{Location of aneurysms}

- Fig. 1 shows the location of aneurysms; accordingly, 72.4\% [84.8\%] of aneurysms involved the abdominal aorta. As a subcategory of the 1186 abdominal aortic aneurysms treated, infrarenal AAA accounted for the largest proportion of all AAAs treated with 904 cases, representing 55.2\% [53.7\%] of the total cohort.

The ascending aorta and aortic arch were reported in $1.1 \%$ [0.7\%] and $2.8 \%$ [ $2.5 \%]$, respectively, the descending thoracic aorta was treated in $19.3 \%$ [12\%], and the thoracoabdominal junction was newly recorded in $4.5 \%$ of cases.

Among EVARs treated outside routine daily hours, thoracic aneurysms accounted for a larger proportion (39.6\%) than among those treated during routine service (23.2\%). Infrarenal AAAs continued to account for the largest share with 42 cases (43.8\%).

\section{Aneurysm type}

- Table 1 provides an overview of treated aneurysm types.

Although only 881 data records could be evaluated in 2011, this was possible for all data records in 2019. The percentage distribution of aneurysm types treated was comparatively largely unchanged. In contrast, the proportion of treated dissections increased by just over one-third ( $10.8 \%$ vs. $6.5 \%$ ).

With respect to emergency EVAR procedures, a different picture emerges based on the emergency indication. In this case, true aneurysms account for only $33.3 \%$, whereas dissections (21.9\%), hidden perforations (30.2\%), and free perforations (9.4\%) occupy a higher proportion. Pseudoaneurysms accounted for $4.2 \%$ of emergency indications.

\section{Aneurysm diameter}

Whereas in 2011, information on the diameter of treated aneurysms was voluntarily provided in only 772 of 1167 cases $(66 \%)$, this is mandatory information in the current version of 
- Table 1 Overview of aneurysm types treated in $2019(n=1639)$ compared with $2011(n=881)$.

\begin{tabular}{|c|c|c|c|c|}
\hline \multirow[b]{2}{*}{ aneurysm type } & \multicolumn{2}{|l|}{2019} & \multicolumn{2}{|l|}{2011} \\
\hline & $\mathbf{n}$ & percentage & $\mathbf{n}$ & percentage \\
\hline true aneurysm & 1262 & $77.0 \%$ & 700 & $79.5 \%$ \\
\hline pseudoaneurysm & 61 & $3.7 \%$ & 36 & $4.1 \%$ \\
\hline dissection & 177 & $10.8 \%$ & 57 & $6.5 \%$ \\
\hline hidden perforation & 110 & $6.7 \%$ & 66 & $7.5 \%$ \\
\hline free perforation & 13 & $0.8 \%$ & 11 & $1.2 \%$ \\
\hline non-infectious inflammation & 13 & $0.8 \%$ & 9 & $1.0 \%$ \\
\hline infection (mycotic aneurysm) & 3 & $0.2 \%$ & 2 & $0.2 \%$ \\
\hline total & 1639 & $100 \%$ & 881 & $100 \%$ \\
\hline
\end{tabular}

the DeGIR database. Also, in the past aneurysms smaller than $50 \mathrm{~mm}$ were not coded.

- Fig. 2 shows the percentage distribution of the treated aortic aneurysm parameters according to the coded size intervals for the total of all EVAR and emergency treatments. Accordingly, $54 \%$ of all treated aneurysms had a size between 50 and $70 \mathrm{~mm}$, whereas in emergency EVARs, the indication for treatment of larger aneurysms $(\geq 70 \mathrm{~mm})$ and smaller ectasias $(\leq 30 \mathrm{~mm})$ was more frequent in percentage.

\section{Process Data}

Anesthesia types during intervention

Recording of analgesia and/or sedation during EVAR intervention has been newly introduced in the current version of the DeGIR QA system compared to 2011.

According to $>$ Fig. 3, 93.3\% of all EVAR procedures were performed under intubation anesthesia and $6.7 \%$ under analgesia. Due to the existing possibility of multiple responses, local anesthesia could be coded additionally. Local anesthesia was documented as the sole form of analgesia/anesthesia during intervention in $2.7 \%$ of cases.

\section{Imaging guidance}

In addition to digital subtraction angiography (DSA) as the standard modality, cone beam CT was used in $6.9 \%$ of all EVAR procedures, and sonography was used as a supporting method in $5.9 \%$ of procedures. In emergency interventions, the proportion of cone beam CT for imaging guidance increased to $18.3 \%$, while sonography was still used in $7.3 \%$.

\section{Arterial access route}

Compared to 2011 , the arterial access route was newly recorded as a mandatory field in 2019. Because a decision is required for each individual issue (femoral percutaneous, femoral surgical, brachial artery percutaneous, brachial artery surgical), multiple responses are possible in different categories simultaneously. There was an even distribution between surgical and percuta- neous access, each with a share of about $50 \%$. Additional access via the brachial arteries had been documented to a much lesser extent (percutaneous $8.1 \%$; surgical $5.2 \%$ ).

Of EVAR interventions, $49.2 \%$ were performed under difficult conditions with "difficult access route" documented as a cause in $17.9 \%$ of such cases.

\section{Treatment of arterial access routes}

- Fig. 4 provides an overview of the techniques used to treat interventional access routes, a new mandatory feature of the DeGIR registry database with the option of multiple responses.

Surgical procedures to close the vascular access were consequently involved in a total of $57.5 \%$ of cases and were used in $49.5 \%$ of cases as the sole primary procedure without other aids. Among vascular closure devices (VCDs) frequently used alone or in combination, suture- and fibrin-based devices are strong leaders at $35.6 \%$ and $19.8 \%$, respectively. Clip-based devices play a subordinate role with a share of $1.5 \%$. Manual compression was used more frequently than instrument-assisted compression by a factor of 8 . This was involved in one in five cases overall, but extremely rarely reported as the sole method of treating the arterial access route in only $0.9 \%$ of cases. As a supportive measure, it was mostly used in combination with suture-based VCD, followed by fibrin-based VCD or surgical procedures. A three-fold combination of surgical closure, manual compression, and at least one VCD was rarely necessary (3.3\% of all interventions). The theoretically equally selectable option of a simple bandage was not documented in any case.

\section{Quality of EVAR outcomes}

- Table 2 shows the outcome quality of EVAR procedures including the new mandatory quality parameter "correct stent graft placement". Correct stent graft placement was achieved in $98.9 \%$ of the total cohort and $96.9 \%$ of the emergency EVAR procedures. The reasons for 14 abortions ( $0.9 \%$ ) were of a technical-anatomical nature in five cases or due to complications that were dependent on or independent of the intervention in one and three cases, respectively. The causes of the remaining five cases were not specified. 
$60 \%$

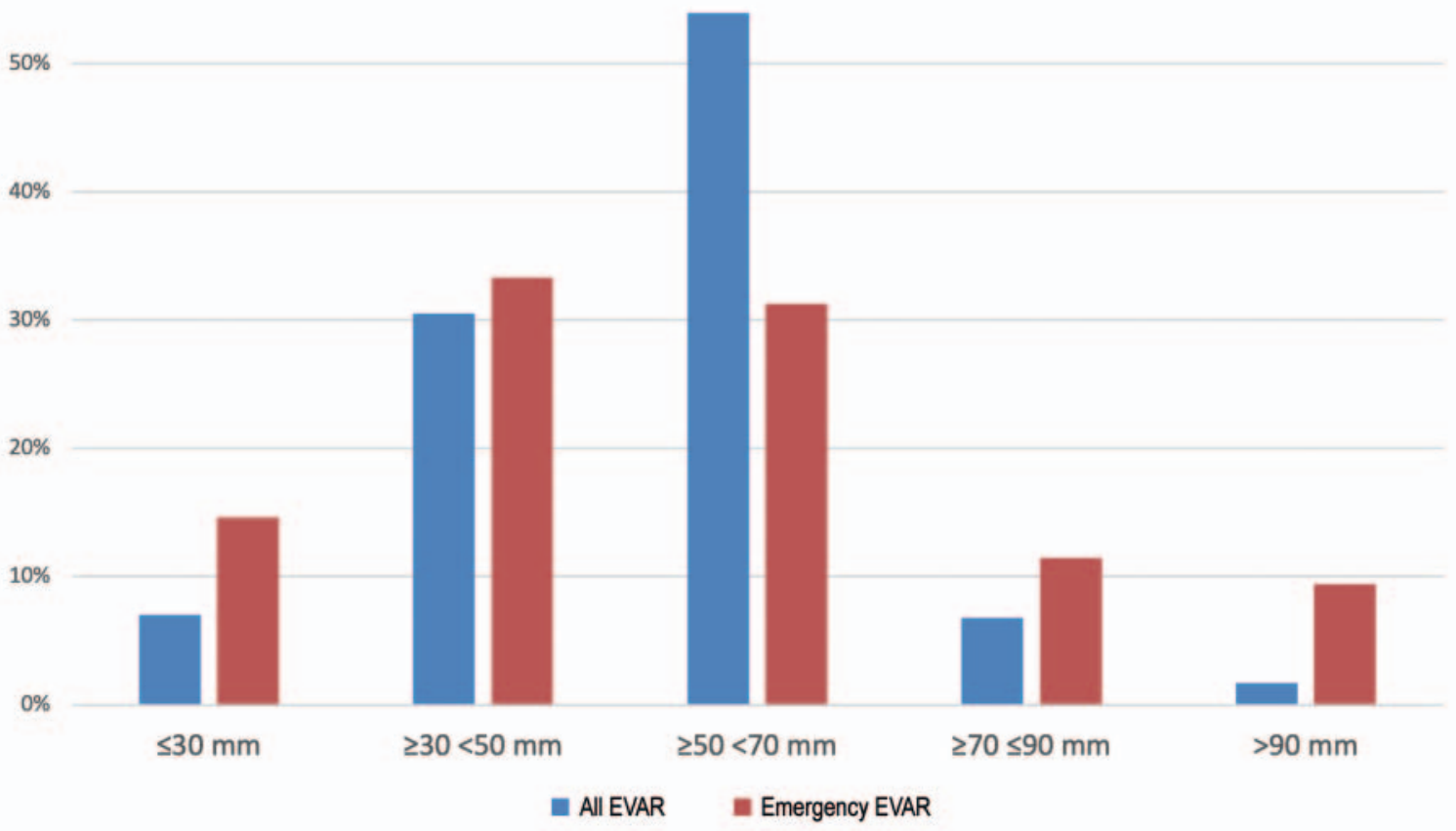

Fig. 2 Diameters of all aortic aneurysms receiving elective and emergency treatment in 2019 ( $n=1639)$.

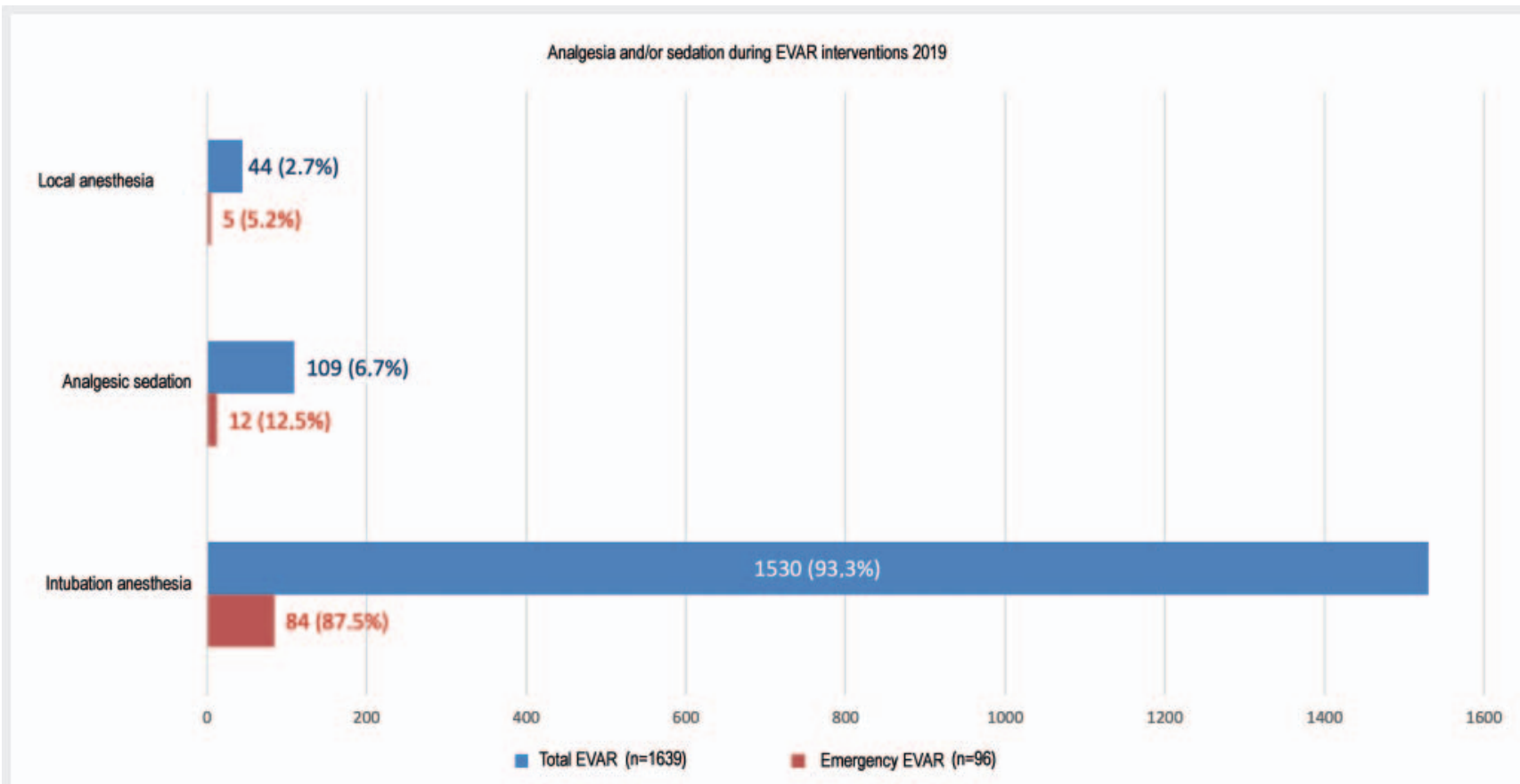

- Fig. 3 Form of anesthesia during aneurysm treatment in 2019 including emergency EVAR. The DeGIR registry database allows multiple responses. 


\section{Treatment of interventional access route 2019 (n-1639)}

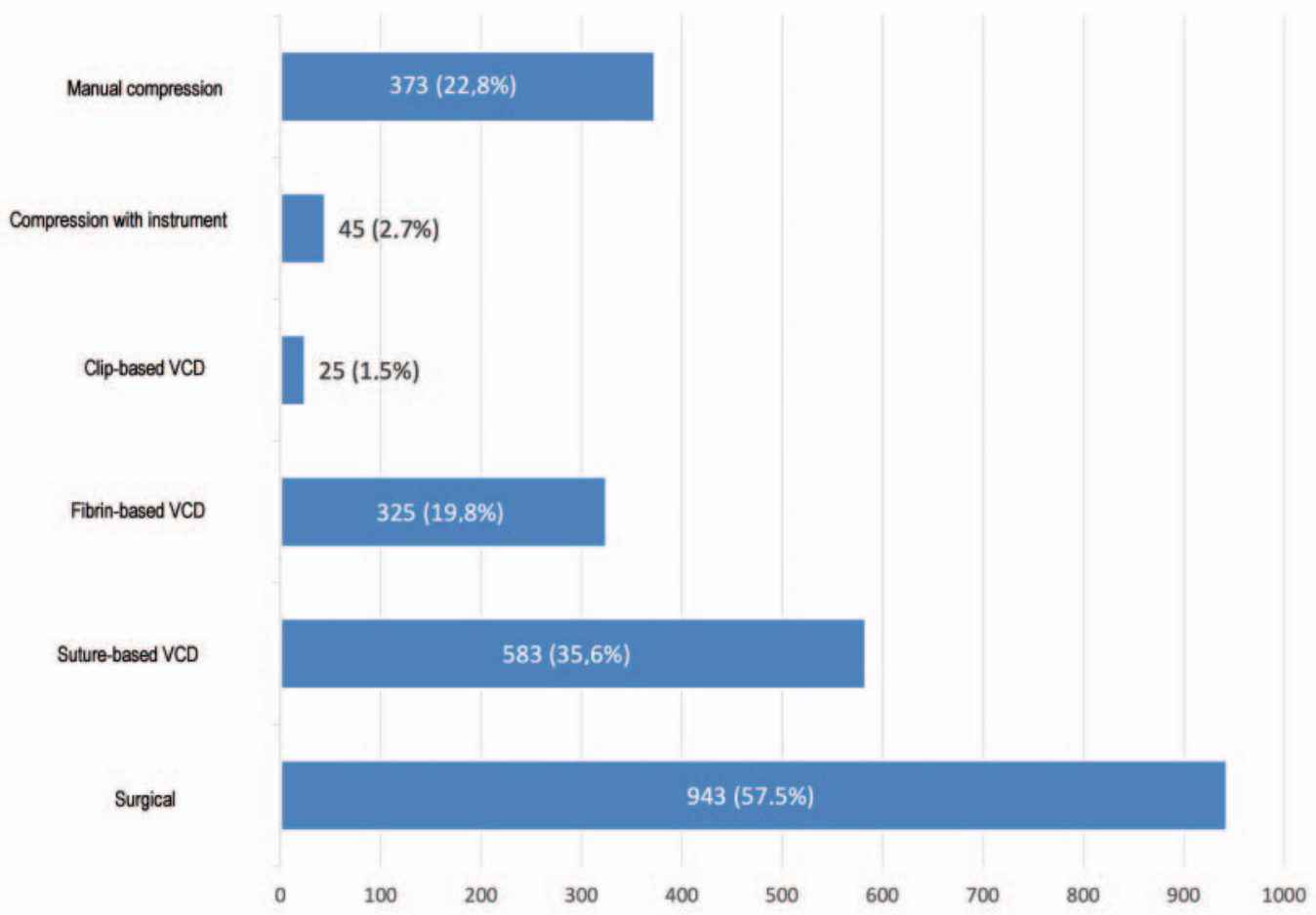

- Fig. 4 Overview of techniques used to provide interventional access. This is a mandatory entry and the DeGIR registry database allows multiple entries. (VCD = vascular closure device).

Primary endoleaks occurred in $13.8 \%$ of EVARs [12.8\%] and $8.3 \%$ of emergency EVARs. Accordingly, clinical success defined as the absence of a primary endoleak was $86.2 \%$ [87.2\%] for elective procedures and $91.7 \%$ for emergency EVARs. In 2011 emergency treatments were not specifically considered with regard to endoleaks.

The mean intervention time of an EVAR was given as $129.6 \mathrm{~min}$ (median $110 \mathrm{~min}$, range 10-705 min). An emergency EVAR lasted an average of 131 minutes (median 120 minutes, range 20-293 minutes).

\section{Implanted prosthesis types}

- Table 3 offers an overview of the coded prosthesis types. The proportion of bifurcation prostheses decreased from $64.7 \%$ in 2011 to $39.9 \%$ in 2019 . At the same time, the proportion of tubular prostheses increased to $27.4 \%$ [20.5\%] and the proportion of fenestrated and combined prostheses increased to $17.3 \%$ [3.3\%] and $11.3 \%$ [6.1\%], respectively.

In the emergency EVAR group, tubular prostheses were used in $48.7 \%$ [63.9\%], bifurcation prostheses in $19.2 \%$ [20.8\%], and aortomonoiliac stent grafts in $11.5 \%$ [13.9\%] of cases. The relatively frequent use of fenestrated prostheses in an emergency setting is a novelty compared to 2011 with $12.8 \%$. Combined prostheses were also used more frequently on an emergency basis at $3.8 \%[1.4 \%]$.

\section{Technical success, endoleaks (partial success) and failure}

- Table 4 shows the rates for success, partial success, technical success and failure in tabular form - broken down by the respective stent graft type - in year-to-year comparison. The success rate (correct placement without any endoleak) for all interventions is $84.8 \%$ [ $89 \%$ ], and the rate of correctly-placed stent grafts with primary endoleaks type II or type IV (partial success) is $8 \%$ [8.4\%].

Since type II and IV endoleaks are not process-associated, they were by definition included in the "technical success" group, the overall rate of which is $92.8 \%$ [94.5\%]. Therapy failures (intervention discontinuation or malposition or type I or type III endoleaks) were documented in $7.2 \%$ [5.6\%] of cases. With respect to individual prosthesis types, the level of technical success remained high compared to 2011 at 93.1-94.4\%. Fenestrated prostheses and aortomonoiliac prostheses had lower technical success rates of $90.7 \%$ and $88.6 \%$, respectively.

The success rate of emergency EVAR procedures ( $\triangleright$ Table 5 ) was $89.7 \%$. Although fenestrated and combined prostheses were used $100 \%$ successfully, in the case of iliac bifurcation prostheses, one of the three emergencies failed, contrary to the general success rate of $94.4 \%$. 
- Table 2 Quality of results of EVAR interventions ( $n=1639)$ including emergency EVAR ( $n=96)$ in 2019 compared with EVAR in 2011, as measured by correct prosthesis placement, clinical success (= absence of primary endoleak), and number of intervention discontinuations.

\begin{tabular}{|c|c|c|c|c|c|c|}
\hline \multirow[b]{3}{*}{ quality parameter } & \multicolumn{4}{|c|}{ EVAR total } & \multirow{2}{*}{\multicolumn{2}{|c|}{$\begin{array}{l}\text { emergency EVAR } \\
2019\end{array}$}} \\
\hline & \multicolumn{2}{|l|}{2019} & \multicolumn{2}{|c|}{2011} & & \\
\hline & $\mathbf{n}$ & $\begin{array}{l}\text { percen- } \\
\text { tage }\end{array}$ & $\mathbf{n}$ & $\begin{array}{l}\text { percen- } \\
\text { tage }\end{array}$ & $\mathbf{n}$ & percentage \\
\hline proper placement & 1621 & $98.9 \%$ & \multicolumn{2}{|c|}{ not recorded } & 93 & $96.9 \%$ \\
\hline no endoleak & 1412 & $86.2 \%$ & 823 & $87.2 \%$ & 88 & $91.7 \%$ \\
\hline primary endoleak & 227 & $13.8 \%$ & 121 & $12.8 \%$ & 8 & $8.3 \%$ \\
\hline - Type I & 77 & $4.7 \%$ & 37 & $3.9 \%$ & 5 & $5.2 \%$ \\
\hline - Type II & 113 & $6.9 \%$ & 79 & $8.4 \%$ & 1 & $1.0 \%$ \\
\hline - Type III & 15 & $0.9 \%$ & 4 & $0.4 \%$ & 2 & $2.1 \%$ \\
\hline - Type IV & 18 & $1.1 \%$ & 1 & $0.1 \%$ & 0 & $0.0 \%$ \\
\hline - No data & 4 & $0.2 \%$ & 0 & $0.0 \%$ & 0 & $0.0 \%$ \\
\hline discontinuations & 14 & $0.9 \%$ & not $\mathrm{r}$ & & 4 & $4.2 \%$ \\
\hline total & \multicolumn{2}{|l|}{1639} & \multicolumn{2}{|l|}{944} & \multicolumn{2}{|l|}{96} \\
\hline
\end{tabular}

- Table 3 Overview of prosthesis types used in comparison between 2019 and 2011, based on all usable records with data for the total EVAR and emergency procedure population. Non-specified prostheses (2011 database) were not included in the analysis. The category "fenestrated" subsumes all prostheses with fenestrations, side branches, chimneys, snorkels, etc.

\begin{tabular}{|c|c|c|c|c|c|c|c|c|}
\hline \multirow[b]{3}{*}{ prosthesis type } & \multicolumn{4}{|c|}{ EVAR total } & \multicolumn{4}{|c|}{ emergency EVAR } \\
\hline & \multicolumn{2}{|l|}{2019} & \multicolumn{2}{|c|}{2011} & \multicolumn{2}{|c|}{2019} & \multicolumn{2}{|c|}{2011} \\
\hline & $\mathbf{n}$ & percentage & $\mathbf{n}$ & percentage & $\mathbf{n}$ & percentage & $\mathbf{n}$ & percentage \\
\hline tubular prosthesis & 423 & $27.4 \%$ & 187 & $20.5 \%$ & 38 & $48.7 \%$ & 46 & $63.9 \%$ \\
\hline bifurcation prosthesis & 617 & $39.9 \%$ & 591 & $64.7 \%$ & 15 & $19.2 \%$ & 15 & $20.8 \%$ \\
\hline aortomonoiliac & 44 & $2.8 \%$ & 49 & $5.4 \%$ & 9 & $11.5 \%$ & 10 & $13.9 \%$ \\
\hline iliac bifurcation & 18 & $1.2 \%$ & - & - & 3 & $3.8 \%$ & - & - \\
\hline fenestrated & 268 & $17.3 \%$ & 30 & $3.3 \%$ & 10 & $12.8 \%$ & 0 & $0.0 \%$ \\
\hline combined & 175 & $11.3 \%$ & 56 & $6.1 \%$ & 3 & $3.8 \%$ & 1 & $1.4 \%$ \\
\hline total & \multicolumn{2}{|l|}{1545} & \multicolumn{2}{|l|}{913} & \multicolumn{2}{|l|}{78} & \multicolumn{2}{|l|}{72} \\
\hline
\end{tabular}

\section{Complications}

\section{Local access route complications}

- Table 6 specifies the occurrence of local vascular complications of the arterial access routes as a function of the post-interventional closure of the access route. Of 1495 evaluable interventions, local complications occurred in 37 cases (2.5\%), including 16 hemorrhages (1.1\%), 15 vascular occlusions (1\%), and 6 aneurysms ( $0.4 \%)$. The use of a fibrin-based VCD was identified as the safest way to treat the vascular access, with a complication rate of $0.6 \%$, followed by primary surgical closure (1.4\%). Suture (3.6\%) and clip-based closure systems (9.1\%) performed worse. The need for secondary use of surgical procedures (a total of
$3.3 \%$ of all interventions) in addition to the vascular closure system was also associated with an increased complication rate for all procedures.

\section{Percentage and severity according to SIR}

Complications occurred in 109 of the 1639 EVAR procedures (6.7\%), a $2.7 \%$ increase in the complication rate compared to 2011 data. The well-established classification of the Society of Interventional Radiology (SIR) [4] was used for stratification of complication levels ( $\triangleright$ Table 7, 8).

Complications occurring within the first 24 hours were recorded as early complications; otherwise they were identified as late complications. The proportion of early complications, 


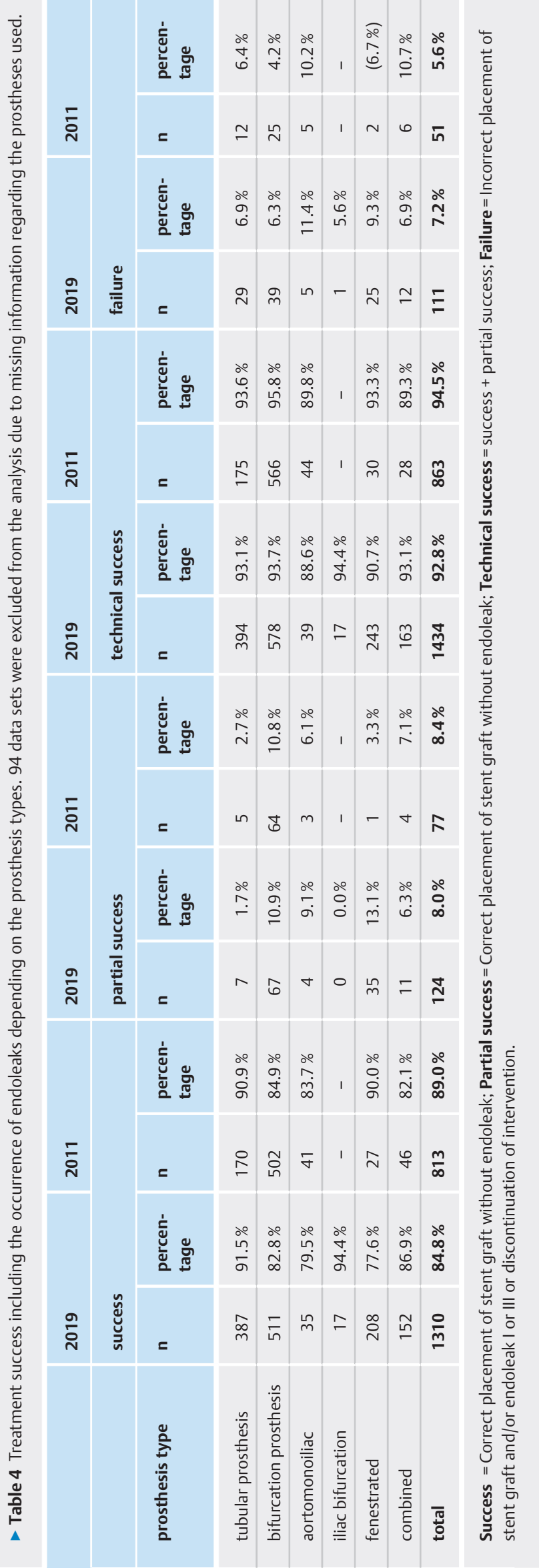

$4.3 \%$, was almost twice as high as that of late complications, $2.4 \%$. It must be emphasized, however, that this also includes complications that are subsequently resolved. For example, the failure of a closure system was considered a complication in principle, even if persistent bleeding could be resolved by the use of another closure system or by surgical intervention.

- Table 7 lists treatment of complications. Sixty-seven of 109 complications (61.4\%) were successfully resolved by the interventionalist alone or by a different discipline. Successful treatment was not possible in 35 cases ( $2.1 \%$ of the total cohort), despite the need for therapy, which is consistent with the otherwise frequently reported overall complication rate for EVAR procedures. After 24 hours, 11 of the patients with early complications $(15.7 \%)$ developed a further complication. The development of a second late complication (> $24 \mathrm{~h}$ ) after initial early complication was associated with a mortality of $36 \%$.

The most frequent early complications were arterial hemorrhages with a proportion of $22.7 \%$, corresponding to an incidence of $0.9 \%$ in relation to the total cohort (each indicated in parentheses), followed by arterial vascular occlusion and neuro-cerebral complications, each with $16.7 \%$ ( $0.7 \%$ related to the total cohort), and cardiac complications with $12.1 \%$ (0.5\%). The most common late complications were arterial vascular occlusion and pulmonary complications, each with $16.2 \%$ (0.4\%), followed by organ dysfunction/failure with $13.5 \%$ (0.3\%). The remaining complication types were in the single-digit percentage range.

In Table 8, it is notable that the proportion of major (grade $\mathrm{C}-\mathrm{F}$ ) complications - irrespective of the distinction between elective and emergency treatments - is almost $90 \%$. Based on all patients treated, the major complication rate increased from $3.1 \%$ to $6 \%$ compared to 2011. For emergency EVAR, the major complication rate reaches nearly $20 \%$ and $9 \%$ for elective fenestrated EVAR.

\section{Mortality}

In 20 cases, complications led to death, resulting in an overall mortality of $1.2 \%$ [1.11\%]. Seven of the deaths were attributable to emergency EVAR in the context of visible or hidden perforation, dissection, or true aneurysm, yielding a mortality of $7.3 \%$ [12\%] for this subgroup. Consideration of elective EVAR alone indicates a mortality of $0.84 \%$ [0.34\%].

Taking into account the first 24 hours post-procedure, 11 patients died - of arterial hemorrhage or cardiac complications. Over a period of 7 days, an additional 5 patients died of arterial vascular occlusion, organ dysfunction/failure, or parenchymal ischemia or infarction. Within the first 30 days, an additional 4 patients died of arterial hemorrhage, parenchymal hemorrhage, organ dysfunction/failure, or pulmonary complications.

\section{Radiation Exposure Data}

Partially implausible data were coded into the mandatory field dose area product (DAP) and fluoroscopy time. Outliers that varied more than 1.5 times the interquartile range from the upper or lower quartile were excluded. The resulting box plot of the dose area product is contained in $>$ Fig. $\mathbf{5}$. 
- Table 5 Treatment success including the occurrence of endoleaks depending on the prosthesis types in emergency EVARs. 18 data sets were excluded from the analysis due to missing information regarding the prostheses used.

\begin{tabular}{|c|c|c|c|c|c|c|c|c|}
\hline \multirow[b]{2}{*}{ prosthesis type } & \multicolumn{2}{|c|}{ success } & \multicolumn{2}{|c|}{ partial success } & \multicolumn{2}{|c|}{ tech. success } & \multicolumn{2}{|c|}{ failure } \\
\hline & $\mathbf{n}$ & percentage & $\mathbf{n}$ & percentage & $\mathbf{n}$ & percentage & $\mathbf{n}$ & percentage \\
\hline tubular prosthesis & 33 & $86.8 \%$ & 0 & $0.0 \%$ & 33 & $86.8 \%$ & 5 & $13.2 \%$ \\
\hline bifurcation prosthesis & 14 & $93.3 \%$ & 0 & $0.0 \%$ & 14 & $93.3 \%$ & 1 & $(6.7 \%)$ \\
\hline aortomonoiliac & 8 & $88.9 \%$ & 0 & $0.0 \%$ & 8 & $88.9 \%$ & 1 & $11.1 \%$ \\
\hline iliac bifurcation & 2 & $66.7 \%$ & 0 & $0.0 \%$ & 2 & $66.7 \%$ & 1 & $33.3 \%$ \\
\hline fenestrated & 10 & $100.0 \%$ & 0 & $0.0 \%$ & 10 & $100.0 \%$ & 0 & $0.0 \%$ \\
\hline combined & 3 & $100.0 \%$ & 0 & $0.0 \%$ & 3 & $100.0 \%$ & 0 & $0.0 \%$ \\
\hline total & 70 & $89.7 \%$ & 0 & $0.0 \%$ & 70 & $89.7 \%$ & 8 & $10.3 \%$ \\
\hline
\end{tabular}

- Table 6 Incidence of local vascular complications of the arterial access routes as a function of the type of postinterventional closure. For analysis, 144 records combining different vascular closure devices (VCDs) were excluded.

\begin{tabular}{|c|c|c|c|c|c|c|}
\hline \multirow[b]{2}{*}{ procedure } & \multirow[b]{2}{*}{$\mathbf{n}$} & \multirow[b]{2}{*}{ percentage* } & \multicolumn{4}{|c|}{ 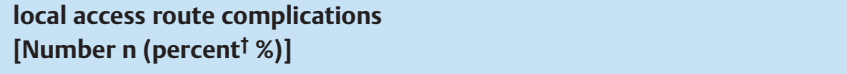 } \\
\hline & & & hemorrhage & aneurysm & vessel closure & total \\
\hline VCD clip-based & 20 & $1.2 \%$ & $1(5 \%)$ & $1(5 \%)$ & $1(5 \%)$ & $3(15 \%)$ \\
\hline Self \pm compression & 11 & $0.7 \%$ & 1 (9.1\%) & 0 & 0 & 1 (9.1\%) \\
\hline Surgically & 9 & $0.5 \%$ & 0 & $1(11.1 \%)$ & $1(11.1 \%)$ & $2(22.2 \%)$ \\
\hline VCD fibrin-based & 205 & $12.5 \%$ & $1(0.5 \%)$ & $1(0.5 \%)$ & 0 & $2(1 \%)$ \\
\hline Self \pm compression & 165 & $10.1 \%$ & $1(0.6 \%)$ & 0 & 0 & $1(0.6 \%)$ \\
\hline Surgically & 40 & $2.4 \%$ & 0 & $1(2.5 \%)$ & 0 & $1(2.5 \%)$ \\
\hline VCD suture-based & 458 & $27.9 \%$ & $9(2 \%)$ & $4(0.9 \%)$ & $8(1.7 \%)$ & $21(4.6 \%)$ \\
\hline self \pm compression & 389 & $23.7 \%$ & $4(1 \%)$ & $3(0.8 \%)$ & $7(1.8 \%)$ & 14 (3.6\%) \\
\hline surgically & 69 & $4.2 \%$ & $5(7.2 \%)$ & $1(1.4 \%)$ & $1(1.4 \%)$ & $7(10.1 \%)$ \\
\hline primary surgical closure & 812 & $49.5 \%$ & $5(0.6 \%)$ & 0 & $6(0.7 \%)$ & $11(1.4 \%)$ \\
\hline total (proportion ${ }^{\dagger}$ ) & 1495 & $91.2 \%$ & $16(1.1 \%)$ & $6(0.4 \%)$ & 15 (1\%) & 37 (2.5\%) \\
\hline
\end{tabular}

The median DFP for total EVAR was $10503 \mathrm{cGy} \times \mathrm{cm}^{2}$ with interquartile range (IQR) $17351 \mathrm{cGy} \times \mathrm{cm}^{2}$ (Q25: $3689 \mathrm{cGy} \times$ $\mathrm{cm}^{2}$, Q75: $\left.21041 \mathrm{cGy} \times \mathrm{cm}^{2}\right)$, for fenestrated prostheses 14217 cGy $\times \mathrm{cm}^{2}$ with IQR $23985 \mathrm{cGy} \times \mathrm{cm}^{2}$ (Q25: $6098 \mathrm{cGy} \times \mathrm{cm}^{2}$, Q75: $30082 \mathrm{cGy} \times \mathrm{cm}^{2}$ ), and for combined prostheses 13021 cGy $\times \mathrm{cm}^{2}$ with IQR $20405 \mathrm{cGy} \times \mathrm{cm}^{2}$ (Q25: $5724 \mathrm{cGy} \times \mathrm{cm}^{2}$, Q75: $\left.26129 \mathrm{cGy} \times \mathrm{cm}^{2}\right)$.

A comparison of the 2011 data to the 2019 data shows that the median DFP for all EVAR 2019 of $10503 \mathrm{cGy} \times \mathrm{cm}^{2}$ is barely different from the 2011 data of $10677 \mathrm{cGy} \times \mathrm{cm}^{2}$. Both values lie in the lower range of the guideline values specified by DeGIR (1500-55000 cGy × $\mathrm{cm}^{2}$ ).
The mean \pm standard deviation of fluoroscopy time in 2019 was $29.3 \pm 27.3 \mathrm{~min}$ for the entire EVAR, $40.1 \pm 33.3 \mathrm{~min}$ for combined prostheses, and $48.5 \pm 35.3 \mathrm{~min}$ for fenestrated prostheses. Median fluoroscopy times were currently 20 min [2011: 17.32 min] for all EVAR interventions, 30 min for combined prostheses, and $43 \mathrm{~min}$ for fenestrated prostheses, again within the range of DeGIR guidelines of 10 to 70 min.

The intervention-only time for all EVARs is mean \pm standard deviation $132.3 \pm 85.7 \mathrm{~min}$ (median $114 \mathrm{~min}$ ), for combined prostheses $154.4 \pm 103.2 \mathrm{~min}$ (median $130 \mathrm{~min}$ ), and for fenestrated prostheses $184.2 \pm 110.7 \mathrm{~min}$ (median $171 \mathrm{~min}$ ). 
- Table 7 Overview of the numbers and percentages of early $(<24 \mathrm{~h})$ and late $(>24 \mathrm{~h})$ complications that occurred after 1639 EVAR procedures, coded based on the degree of complication according to SIR. Breakdown of treatment of complications by own or other disciplines including treatment success.

\begin{tabular}{|c|c|c|c|c|c|c|c|}
\hline \multirow[b]{2}{*}{ complications $<24 \mathrm{~h}$} & \multirow[b]{2}{*}{$\mathbf{n}$} & \multirow[b]{2}{*}{ percentage } & \multirow[b]{2}{*}{ self-treated } & \multirow[b]{2}{*}{$\begin{array}{l}\text { treated } \\
\text { by other } \\
\text { discipline }\end{array}$} & \multirow[b]{2}{*}{$\begin{array}{l}\text { successfully } \\
\text { treated }\end{array}$} & \multicolumn{2}{|c|}{$\begin{array}{l}\text { treatment requirement + } \\
\text { not successfully treated }\end{array}$} \\
\hline & & & & & & $\mathbf{n}$ & percentage \\
\hline A - no treatment required & 4 & $0.2 \%$ & - & - & - & 0 & $0.0 \%$ \\
\hline B - symptomatic treatment & 3 & $0.2 \%$ & 2 & 0 & 2 & 1 & $0.1 \%$ \\
\hline $\begin{array}{l}\mathrm{C}-\text { treatment required, brief } \\
\text { hospitalization }(<48 \mathrm{~h})\end{array}$ & 12 & $0.7 \%$ & 4 & 6 & 10 & 2 & $0.1 \%$ \\
\hline $\begin{array}{l}\text { D - greater treatment requirement } \\
\text { hospitalization }(>48 \mathrm{~h})\end{array}$ & 33 & $2.0 \%$ & 12 & 15 & 26 & 7 & $0.4 \%$ \\
\hline $\mathrm{E}$ - permanent damage & 7 & $0.4 \%$ & 1 & 5 & 3 & 4 & $0.2 \%$ \\
\hline F - death & 11 & $0.7 \%$ & - & - & - & 11 & $0.7 \%$ \\
\hline complications $<24 \mathrm{~h}$ total & 70 & $4.3 \%$ & 19 & 26 & 41 & 25 & $1.5 \%$ \\
\hline \multicolumn{8}{|l|}{ complications $>24 \mathrm{~h}$} \\
\hline A - no treatment required & 3 & $0.2 \%$ & - & - & - & 0 & $0.0 \%$ \\
\hline $\mathrm{B}$ - symptomatic treatment & 1 & $0.1 \%$ & 0 & 1 & 1 & 0 & $0.0 \%$ \\
\hline $\begin{array}{l}\mathrm{C}-\text { treatment required, brief } \\
\text { hospitalization }(<48 \mathrm{~h})\end{array}$ & 4 & $0.2 \%$ & 2 & 2 & 4 & 0 & $0.0 \%$ \\
\hline $\begin{array}{l}\mathrm{D} \text { - greater treatment requirement } \\
\text { hospitalization }(>48 \mathrm{~h})\end{array}$ & 21 & $1.3 \%$ & 8 & 13 & 21 & 0 & $0.0 \%$ \\
\hline $\mathrm{E}$ - permanent damage & 1 & $0.1 \%$ & 0 & 1 & 0 & 1 & $0.1 \%$ \\
\hline F - death & 9 & $0.5 \%$ & - & - & - & 9 & $0.5 \%$ \\
\hline complications $>24 \mathrm{~h}$ total & 39 & $2.4 \%$ & 10 & 17 & 26 & 10 & $0.6 \%$ \\
\hline total complications & 109 & (6.7\%) & 29 & 43 & 67 & 35 & $2.1 \%$ \\
\hline
\end{tabular}

- Table 8 Comparison of the numbers and percentages of complications in the total collective of all EVARs between 2019 and 2011 and the subgroups of emergency EVARs and fenestrated EVARs in 2019, coded according to complication severity by SIR.

\begin{tabular}{|c|c|c|c|c|c|c|c|c|}
\hline \multirow[b]{3}{*}{ degree of complication (SIR) } & \multicolumn{4}{|c|}{ EVAR total } & \multirow{2}{*}{\multicolumn{2}{|c|}{$\begin{array}{l}\text { emergency EVAR } \\
2019(n=96)\end{array}$}} & \multirow{2}{*}{\multicolumn{2}{|c|}{$\begin{array}{l}\text { fenestrated EVAR } \\
2019(n=268)\end{array}$}} \\
\hline & \multicolumn{2}{|c|}{2019 ( $n=1639)$} & \multicolumn{2}{|c|}{$2011(n=1167)$} & & & & \\
\hline & $\mathbf{n}$ & percentage & $\mathbf{n}$ & percentage & $\mathbf{n}$ & percentage & $\mathbf{n}$ & percentage \\
\hline $\operatorname{minor}(A-B)$ & 11 & $0.7 \%$ & 12 & $1.0 \%$ & 2 & $2.1 \%$ & 1 & $0.4 \%$ \\
\hline major (C-F) & 98 & $6.0 \%$ & 36 & $3.1 \%$ & 17 & $17.7 \%$ & 24 & $9.0 \%$ \\
\hline$=\mathrm{C}$ & 16 & $1.0 \%$ & 7 & $0.6 \%$ & 2 & $2.1 \%$ & 4 & $1.5 \%$ \\
\hline - D & 54 & $3.3 \%$ & 15 & $1.3 \%$ & 8 & $8.3 \%$ & 17 & $6.3 \%$ \\
\hline - E & 8 & $0.5 \%$ & 1 & $0.1 \%$ & 0 & $0.0 \%$ & 1 & $0.4 \%$ \\
\hline - $\mathrm{F}$ & 20 & $1.2 \%$ & 13 & $1.1 \%$ & 7 & $7.3 \%$ & 2 & $0.7 \%$ \\
\hline total complications & 109 & $(6.7 \%)$ & 48 & $4.1 \%$ & 19 & $19.8 \%$ & 25 & $9.3 \%$ \\
\hline
\end{tabular}




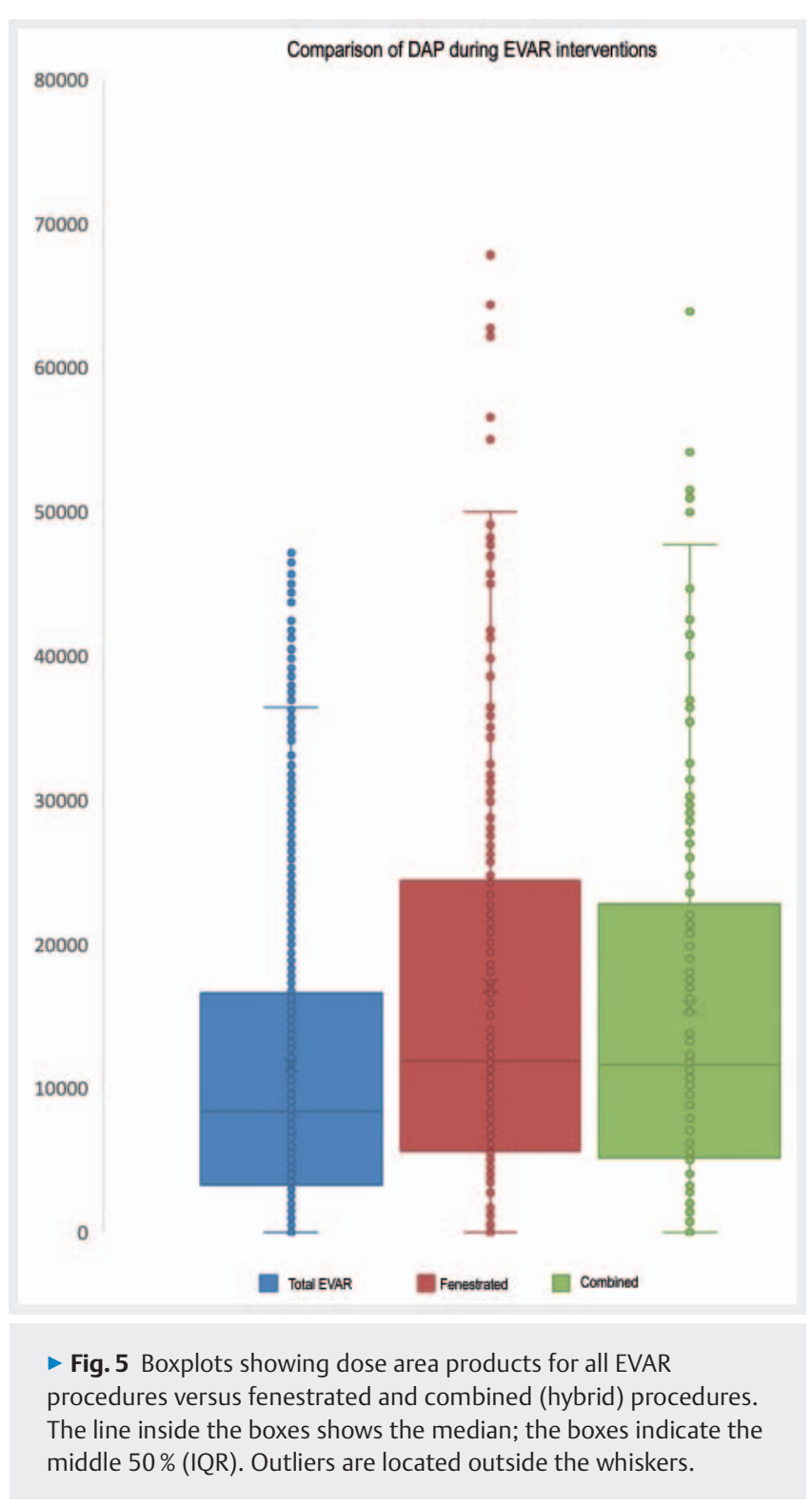

\section{Discussion}

In medicine, quality management has become increasingly important, thus it is not surprising that the DeGIR Quality Assurance Registry, which has existed since 1994, has now grown to almost 200000 coded interventions per year with its voluntarily recorded data.

To address the quality assurance requirements for interventional care of aortic aneurysms, there was increasing implementation of mandatory information in the 2019 DeGIR QA system compared to 2011. This resulted in a greater proportion of complete data sets, allowing a more accurate representation of the reality of care. For example, the new mandatory fields for the parameters "interdisciplinary indication", "aneurysm diameter", "aneurysm type" and "emergency intervention", can be evaluated in 2019 with a significantly improved data situation.

The number of EVAR procedures coded increased $40 \%$ from 2011 to 2019. The sharper increase in the proportion of women treated over time can be explained in part by the gradual equalization of smoking behavior between men and women [5], which may have led to a relative increase in AAA requiring treatment in the female population due to the "smoking" risk factor [6].

In addition, due to the development of prostheses with increasingly smaller diameters and smaller introducers [7], it has become possible to better deal with the female anatomy with its small vessel diameters [8].

\section{Indication}

Interdisciplinary indication is an important quality feature of an optimal, individualized patient treatment. In addition to radiology, the high involvement of vascular surgery in almost every interdisciplinary indication is explained by its position as a department with inpatient beds, and by its role as the most important alternative treatment option of AAA; the quality assurance guideline on abdominal aortic aneurysm of the "Gemeinsamer Bundesausschuss" is also likely to contribute to the involvement of vascular surgery in the interdisciplinary conferences in such cases.

\section{Complexities and complications}

A greater number of complex and increasingly specialized EVAR treatments are now available resulting from technical progress and development of modern prostheses better adapted to the patient's anatomy and, in some cases, easier to implant [7], as well as the growing experience of interventionalists. It is also likely that the use of prostheses outside the instructions for use will become more common as experience is gained. As can be seen in $>$ Table 3, the proportion of fenestrated EVAR procedures has increased fivefold compared with 2011, and combined treatment using multiple prosthesis types has nearly doubled, while the use of simple bifurcation prostheses has decreased by more than one-third.

The high combined technical success of all EVARs of $92.8 \%$ [2011: 94.6] as well as the consistently low complication rate of $6.7 \%$ [ $4.03 \%$ ] can be considered a success in terms of increased expertise of interventional radiologists due to the increasing complexity of treatments and a more widespread use of the procedure over time. A further indication of an increasingly better qualification of the interventionalists can be derived from the following two factors: 1 . The decrease in the use of monoiliac aortic prostheses from $13.9 \%$ to $11.5 \%$ and 2 . The increase in the use of fenestrated prosthesis types (including other complex hybrid types such as chimney technique, etc.) from $3.3 \%$ in 2011 to $17.3 \%$ in 2019.

The slightly higher failure rate of fenestrated EVAR procedures of $9.3 \%$ (compared to $7.2 \%$ failure in the total cohort) compared to other prosthesis types can be explained by the higher complexity of the intervention.

A comparison of the quality of the results of the elective with the emergency procedures shows that the rate of correct placements in emergencies is only $2 \%$ lower ( $99 \%$ vs. $97 \%$ ). In the case of primary endoleaks, emergency care scores $8.3 \%$, significantly better than elective procedures with $13.8 \%$. This is likely due to a bias in patient selection; ruptured abdominal aortic 
aneurysms with a short neck are more likely to receive surgical management. It is encouraging to note that emergency care by qualified interventional radiologists seems to be assured; this can be concluded from an almost identical intervention time for elective and emergency procedures. However, this hypothesis must be qualified by the bias in patient selection mentioned above. The $100 \%$ success rate of all complex aortic prostheses (fenestrated, chimney, etc.) in emergency use and, moreover, without endoleaks, cannot be cited as a further argument for improved patient care due to the small number of 10 cases, even though no fenestrated prostheses in 2011 were used in emergency care.

Consideration of complication rates during the period 2011 to 2019 could give rise to the opposite conclusion, as major complications have increased from $3.1 \%$ to $6 \%$. However, the overall complication rate after successful resolution of the initial complication must be considered; for all complications this is $2.1 \%$ and for major complications $2 \%$. The increase in the number of cases with greater complexity must also be taken into account; as expected, elective complex EVAR procedures with a complication rate of $9 \%$ is above the average overall complication rate. The increasing complexity of the interventions can be seen from the overall higher values for the fluoroscopy time, dose area product and intervention time. As seen in $>$ Table 7, treatment of complications by either the intervention team or a consulted discipline resulted in successful completion of treatment for early and late complications in $58.6 \%$ and $66.7 \%$, respectively. Most publications on treatment of aortic aneurysms distinguish only between success, failure and complications affecting outcome. The differentiation introduced in our study, on the other hand, delineates not only the entire treatment process, but also problems and treatment options that need to included in a quality management program, although they do not necessarily affect the outcome.

\section{Arterial access route treatment}

Data on access route treatment show very high interdisciplinary involvement in primarily vascular surgical closure of pathways in almost $49.5 \%$ of cases with a low local complication rate of $1.4 \%$. Of the vascular closure systems used, only fibrin-based systems used alone in $10.1 \%$ achieved a lower complication rate of $0.6 \%$. Suture-based systems, which were more than twice as common in $23.7 \%$, achieved a sixfold higher rate of complications (3.6\%). The high complication rate of $9.1 \%$ for clip-based closure systems is not meaningful due to their infrequent use at $0.7 \%(n=11)$.

The need for secondary surgical closure despite the use of a vascular closure system was rare, accounting for $3.3 \%$ of cases, thus frequently used closure systems may be said to function satisfactorily.

\section{Radiation exposure}

Depending on the type, complexity, and duration of the procedure used in radiological interventions, radiation doses may vary but these doses should be in the nondeterministic (stochastic) range to prevent direct radiation damage to the patient. The patient dose applied during an intervention is thus an essential quality characteristic. Entry of values for the dose area product and fluoroscopic time disclosed a small proportion of implausible values, as these values are stated by the individual device manufacturers in different powers of ten and have to be converted accordingly. For this purpose, a custom tool was implemented in new versions of the software. It was possible to eliminate the few extremely outlying values by calculating the quartiles and box plots. Fortunately, the dose values were both within the range specified by DeGIR for EVAR interventions and below the reference values for diagnostic and interventional X-ray applications published by the German Federal Office for Radiation Protection (BfS) [9]. The distribution of dose area products for all EVAR procedures versus the more complex procedures of fenestrated or combined prostheses shows a lower median. The data presented indicate that separate values for standard and complex prosthesis types should be established for the possible determination of dose reference values for EVAR procedures.

\section{Conclusions}

Data analysis of the DeGIR quality assurance system demonstrates a consistently very high technical success rate for EVAR procedures performed by interventional radiologists with a constant low complication rate. The Quality Registry provides the necessary basis for demonstrating the current reality of care. Registration of the individual process data and complication management supports a more in-depth view of the entire therapy process and provides valuable data for the further development of quality management. In order to ensure the comparability of the controversial long-term results from studies in other European countries with Germany, it would be desirable to supplement the DeGIR QA system with a functionality for follow-up controls and re-interventions. This would further potentially allow identification of problematic constellations and risk factors for failure, thus further improving the care of patients with AAA using EVAR in the long term.

\section{Conflict of Interest}

The authors declare that they have no conflict of interest.

\section{References}

[1] Heuser L. Qualitätssicherung und Dokumentation in der interventionellen +B52 Gefäßmedizin. Epub ahead of print In: Operative und interventionelle Gefäßmedizin. 2018.2018. doi:10.1007/978-3-662-45856-3_46-1

[2] Bücker A, Gross-Fengels W, Haage $P$ et al. Qualifizierungsleitlinie der Deutschen Röntgengesellschaft (DRG) und der Deutschen Gesellschaft für Interventionelle Radiologie und minimalinvasive Therapie (DeGIR) zur Durchführung interventionell-radiologischer minimalinvasiver Verfahren an Arterien und. RöFo - Fortschritte auf dem Gebiet der Röntgenstrahlen und der Bildgeb Verfahren Epub ahead of print 2012. doi:10.1055/ s-0032-1312756

[3] Heuser L], Arnold CN, Morhard D et al. Qualitätsreport 2011: Bericht über die Behandlungsqualität minimalinvasiver Methoden - Teil 2 Interventionelle Therapie (EVAR) von Aortenaneurysmen. RoFo Fortschritte auf dem Gebiet der Rontgenstrahlen und der Bildgeb Verfahren Epub ahead of print 2013. doi:10.1055/s-0033-1335736 
[4] Society of Interventional Radiology Standards of Practice Committee. Guidelines for Percutaneous Transluminal Angioplasty. J Vasc Interv Radiol Epub ahead of print 2003. doi:10.1097/01. RVI.0000094586.83406.ac

[5] Statistisches Bundesamt (Destatis). Gesundheitsberichterstattung des Bundes - Verteilung der Bevölkerung nach ihrem Rauchverhalten (1992-2017). accessed 14 Mar 2021. https://www.gbe-bund.de/gbe/! pkg_olap_tables.prc_set_orientation?p_uid=gast\&p_aid=7308363\&p_ sprache $=$ D\&p_help $=2 \&$ p_indnr $=436 \&$ p_ansnr $=10864814 \&$ p_ver sion $=6 \& D .000=2 \& D .002=3 \& D .003=1 \& D .469=1$

[6] Carnevale M, Koleilat I, Lipsitz EC et al. Extended Screening Guidelines for the Diagnosis of Abdominal Aortic Aneurysm. J Vasc Surg Epub ahead of print 2020. doi:0.1016/j.jvs.2020.04.321
[7] Maßmann A, Shayesteh-Kheslat R, Frenzel F et al. New developements in endovascular infrarenal aortic aneurysm treatment. Radiologe Epub ahead of print 2018. doi:10.1007/s00117-018-0440-2

[8] Rogers IS, Massaro JM, Truong QA et al. Distribution, determinants, and normal reference values of thoracic and abdominal aortic diameters by computed tomography (from the framingham heart study). Am J Cardiol Epub ahead of print 2013. doi:10.1016/j.amjcard.2013.01.306

[9] Schegerer AA, Loose R, Heuser L et al. Diagnostic reference levels for diagnostic and interventional X-ray procedures in Germany: Update and handling - Answer to the comments of members of the chest radiology workshop of the German Roentgen Society. RoFo Fortschritte auf dem Gebiet der Rontgenstrahlen und der Bildgebenden Verfahren Epub ahead of print 2020. doi:10.1055/a-1064-0559 